\title{
A SEMÂNTICA DE VALOR DE VERDADE E A GRAMÁTICA DE MONTAGUEI
}

\author{
Ana Lúcia Müller*
}

RESUMO: Este artigo discute essencialmente a base filosófica do projeto lingüístico do lógico norteamericano Richard Montague (1930-1970). O objetivo de Montague é a construção de uma Semântica de Valor de Verdade para as línguas naturais através de uma semântica de modelo teórico e de uma semântica de mundos possiveis, fazendo uso de uma linguagem lógica intensional. Em particular, discute-se a opção por uma Semântica de Valor de Verdade e sua validade enquanto instrumento de análise do significado nas línguas naturais.

Palavras-chave: semântica, significado, semântica de valor de verdade.

\section{Apresentação}

Este é um artigo sobre a área da semântica formal, a qual se dedica ao estudo do significado utilizando-se de técnicas das linguagens lógicas. Mais particularmente, este artigo enfoca a semântica de uma teoria conhecida como "Gramática de Montague" elaborada pelo lógico norte-americano Richard Montague (19301970). A Gramática de Montague trata de viabilizar a aplicação de uma semântica de valor de verdade às línguas naturais. Faz isto através da adoção de aparatos lógico-matemáticos como a teoria dos modelos, a concepção de mundos possíveis e a lógica intensional.

A gramática de R. Montague contém uma teoria sintática, uma teoria semântica e uma teoria da tradução. Estas diferentes partes da teoria geral estão interrelacionadas pelo fato de que cada uma delas é concebida como uma álgebra e as estruturas destas três álgebras são idênticas. Montague expõe as bases de sua teoria em um artigo entitulado "Universal Grammar" A aplicação mais completa deste projeto, encontra-se no artigo de Montague(1973) "The proper treatment of quantification in ordinary English"

(*) Professora da Universidade de São Paulo.

(1) Este artigo baseia-se no capítulo 1 de MÜLLER, 1988. 

e Literatura, n. 20, p. 119-136, 1992/1993.

Este trabalho concentra-se na discussão e explicitação dos conceitos apresentados nestes dois artigos. Em particular, expõe e discute a semântica de valor de verdade enquanto instrumento para o estudo do significado nas línguas naturais os problemas e as vantagens desta opção teórica.

\section{A Semântica de Valor de Verdade}

\subsection{A Herança lingüístico-Filośfica de Richard Montague}

Para um estudioso com a formação de nossos cursos de Letras, a Gramática de Montague deve aparecer como algo atípico e difícil de contextualizar. É que a maneira de Montague - um lógico fazer linguística é uma maneira que vem de outra tradição lingüístico filosófica. Montague insere-se na tradição filosófica contemporânea que vem de Frege e de Russell, que perceberam que as sentenças da linguagem natural possuem estruturas semânticas que não correspondem trivialmente à sua estrutura gramatical superficial. Vem desta tradição todo um esforço de formalização da linguagem (Carnap, Quine, o Círculo de Viena), a qual leva muitas vezes a uma negação da possibilidade de se fazer semântica para a linguagem natural, mas leva também ao desenvolvimento de linguagens lógicas cada vez mais sofisticadas capazes de incorporar, por exemplo, modalidades e tempos; e a uma concepção de que linguagens não possuem interpretações absolutas, mas são semanticamente interpretadas em modelos, e em relação a situações e mundos possíveis.

O estudo da linguagem por gramáticos e lingüistas neste século desenvolveu-se à parte desta tradição. Chomsky em seu Syntactic Structures(1957), tenta dar uma definição formal da noção de gramaticalidade (boa-formação) para as sentenças da linguagem natural através de regras sintáticas recursivas. $O$ projeto de Chomsky de formalizar a sintaxe da linguagem natural tenta explicitamente manter-se independente da elaboração de uma semântica para a linguagem natural.

Donald Davidson $(1967,1970)$ traz para a semântica da linguagem natural um insight análogo ao de Chomsky para a sintaxe: as regras de uma gramática devem ser recursivas, pois de outro modo um ser humano não seria capaz de adquirir a sintaxe de uma determinada língua. Segundo Davidson, a produção e a compreensão de significados não pode se dar de maneira diferente, ou seja, a partir de um número finito de significados básicos o falante é competente para produzir $\mathrm{e}$ compreender os infinitos significados passíveis de serem expressos por uma língua. Uma vez explicitadas estas regras recursivas e com uma especificação de significado do vocabulário semântico básico de uma língua, um semanticista seria capaz de estabelecer para cada sentença $s$ da linguagem-objeto, o que esta sentença significa. Ou seja, o semanticista seria capaz de produzir para cada sentença $s$ da linguagem-objeto uma sentença como a expressa em (1). 


\section{(1) $s$ significa que $p$;}

onde $s$ é o nome da sentença que se deseja explicar e $p$ seu significado.

No entanto, a sentença (1) é problemática enquanto parte de uma teoria semântica. A expressão significa traz para a teoria um desvio de uma linguagem totalmente referencial que Davidson deseja evitar (Davidson, 1967). A análise do que seja $p$ é também problemática, pois sintaticamente $p$ é um sintagma nominal, um termo singular, mas o significado de uma expressão não pode ser um nome, deve ser algo que "dê o significado de $s$ "

Davidson recorre, então, à Convenção (T) de Tarski, expressa em (2):

(2) T: 's é verdadeira se e somente se $p$ ',

ou seja, propõe que a sentença " $s$ é verdadeira se, e somente se $p$ "; pode ser considerada equivalente à sentença " $s$ significa que $p$ ", com a vantagem de que na Convenção $(T) p$ expressa um estado de coisas no mundo que pode, então, ser tomado como o significado de $s$. Temos, conseqüentemente, que a sentença é o conceito primitivo para esta teoria do significado, pois é dela que se pode dizer se é verdadeira ou falsa. Temos também uma equivalência entre o significado de uma sentença e suas condições de verdade.

Se a afirmação de Davidson é válida, então tem-se a vantagem de se poder aplicar à teoria do significado, a teoria semântica da verdade de Tarski $(1935,1944)$, uma teoria de condições de verdade já claramente elaborada e implementável.

\subsection{A Definição Formal de Verdade - Tarski}

O objetivo de Tarski em The Concept of Truth in Formalized Languages (1935) é encontrar uma definição de verdade que consiga expressar a idéia intuitiva de que a verdade é aquilo que corresponde à realidade (a concepção clássica). Para Tarski, fazer isso é construir para cada linguagem particular uma definição do termo "sentença verdadeira" Um critério para uma definição semântica da verdade na linguagem natural que corresponde à definição clássica seria, segundo Tarski (1935, p.155), o seguinte:

(3) "uma sentença verdadeira é aquela que diz que o estado de coisa é tal e qual, e o estado de coisas é realmente tal e qual"

Para Tarski, no entanto, as tentativas de formalizar a idéia expressa em (3) para a linguagem natural esbarram com diversos problemas, o principal deles sendo a universalidade desta. Esta universalidade torna a linguagem natural formal- 
mente inconsistente no sentido de que a ela pertencem as expressões e os nomes das expressões e isto é uma fonte de contradições. Ela também contém o vocabulário de uma teoria semântica, ou seja, termos como 'verdade', 'denotação', 'satisfação' etc. A universalidade da linguagem natural tem como consequência o fato de que uma teoria nela elaborada necessariamente contém contradições e leva a paradoxos.

Tarski elabora, então, um critério formal para uma definição de sentença verdadeira que se aplicaria, segundo ele, apenas a linguagens formalizadas que são passiveis de serem descritas por metalinguagens mais poderosas onde estariam contidas e que contém os termos utilizados pela teoria semântica. $O$ critério é conhecido como o Princípio de Equivalência de Tarski, a chamada Convenção (T) já citada em (2), cuja ilustração clássica é o famoso exemplo:

(4) A neve é branca se, e somente se, a neve é branca.

A sentença (4) é uma sentença da metalinguagem na qual se elabora a teoria semântica da verdade. A neve é branca, que substitui a variável metalinguística $s$ na Convenção ( $\mathrm{T}$ ), é o nome desta sentença expresso na metalinguagem e deve ser considerado um termo, não uma oração. A segunda ocorrência de "a neve é branca" substitui $p$ e expressa através da metalinguagem as condições de verdade da sentença cujo nome é a neve é branca. Diz, portanto, como deve ser o mundo para que esta sentença seja verdadeira. Note-se que a Convenção $(T)$ nada revela de novo sobre as condições efetivas sob as quais uma sentença é verdadeira - estas já estão, na verdade, ditas na própria sentença. Qual seria então seu papel numa teoria do significado?

Colocando as condições de verdade como o significado da sentença, a teoria obriga uma busca de como os significados das palavras contribuem para construir estas condições de verdade. Explicar o significado de uma sentença ou das sentenças de uma língua seria, então, explicar como as expressões se estruturam dentro de uma sentença de maneira a determinar que as suas condições de verdade sejam as que são. A semântica trata, então, da relação entre classe sentenças e estados-de-coisas. A palavra "verdadeiro" denota uma classe de sentenças da linguagem-objeto; e a partir do conceito de sentença verdadeira os outros conceitos da teoria semântica podem ser definidos.

\subsection{A Aplicação da Convenção (T) à Linguagem Natural}

Voltemos, então, à proposta de Davidson. Se, ao contrário do que julga Tarski, a Convenção $(T)$ pode ser aplicada à linguagem natural e utilizada por uma teoria do significado, como propõe Davidson, estamos diante de uma teoria que nos oferece várias vantagens: 
(i ) obtém-se uma definição recursiva do significado de uma sentença a partir da definição recursiva de verdade fornecida pela teoria de Tarski. Este é um ponto positivo já que uma definição formal de significado deve ser recursiva.

(ii ) não há necessidade de conceitos semânticos extras, todos os conceitos podem ser definidos a partir do conceito de verdade, que remete a uma relação linguagem-mundo; evitando-se assim a circularidade.

(iii ) Uma teoria da verdade pode prever e explicar várias das características semânticas das sentenças, como a ambigüidade, a implicação, a sinonímia e a verdade lógica.

A aceitação de uma Semântica de Valor de Verdade para as línguas naturais passa, todavia, por uma resposta à questão sobre a universalidade da linguagem natural. Deixaremos, entretanto, esta discussão para mais adiante.

Montague opta por uma Semântica de Valor de Verdade, adotando explicitamente a proposta de Davidson.

"Eu rejeito a afirmação de que existe uma diferença teórica importante entre linguagens formais e línguas naturais. Por outro lado, eu não encaro como bem sucedidos os tratamentos formais da linguagem natural ensaiados por alguns lingüistas contemporâneos. Como Donald Davidson, eu encaro a construção de uma teoria de verdade - ou melhor, da noção mais geral de verdade sob uma interpretação arbitrária - como o objetivo básico de uma sintaxe e de uma semântica sérias;" (Montague, 1970, p.187).

Montague insere-se, então, numa tradição filosófica advinda dos filósofos Frege, Russell, de Wittgenstein do Tractatus Logico-Philosophicus (no qual afirma que as sentenças são figurações da realidade) de Tarski, Carnap, Quine e Davidson. Esta sua herança filosófica.

Montague, no entanto, une a esta herança uma preocupação em respeitar a linguagem natural, pois os estudos feitos por filósofos das formas lógicas e/ou dos significados da sentenças até então nunca haviam explicitado a conexão entre a estrutura superficial de uma sentença e sua semântica. Montague vai tentar a tarefa gigantesca de eliminar o abismo existente entre a tradição lógica e a tradição linguística. As complicações de sua gramática ocorrem principalmente por seu compromisso em respeitar a sintaxe superficial de linguagem natural ao elaborar sua semântica (cf. Stegmuller, 1977).

Como se vê, Montague acredita literalmente na ausência de uma diferença essencial entre a linguagem natural e as linguagens formais dos lógicos e elabora uma descrição da sintaxe e da semântica da linguagem natural dentro de uma mesma teoria lógico-matemática utilizada para linguagens lógicas. 

e Literatura, n. 20, p. 119-136, 1992/1993.

\section{A opção pela semântica de valor de verdade}

Ao optar com uma Semântica de Valor de Verdade, Montague opta por uma maneira particular de responder à questão do que é o significado de uma expressão em uma língua natural. O significado para uma Semântica de Valor de Verdade é uma relação entre a linguagem e algo exterior a ela, a que podemos chamar de mundo ou mundos possíveis. Estes mundos corresponderiam à nossa realidade $\mathrm{e} a$ todas as outras realidades possíveis ou imagináveis; e devem ser pensados como contendo todos os objetos e relações reais ou imaginários aos quais podemos potencialmente nos referir.

Como já foi dito, a relação liguagem-mundo é feita através do conceito de verdade de uma sentença. Conhecer o significado de uma sentença é saber sob que condições ela seria verdadeira, é saber como teria de ser o mundo para que esta sentença fosse verdadeira. Se conhecemos as condições de verdade de uma sentença, conhecemos seu significado, isto é , sabemos realizar a associação linguagemmundo. Como ilustração, consideremos as seguintes sentenças:

(5) A criança brinca com a boneca;

(6) O unicómio conversa com o menino.

Para compreendermos a sentença (6) somos forçados a conceber um mundo em que existe pelo menos um animal semelhante ao cavalo de nosso mundo, mas com um chifre na testa, que é capaz de falar e que, neste momento, fala com uma criança. O mesmo ocorre com nossa compreensão da sentença (5), só que menos obviamente, pois trata-se de nosso próprio mundo.

Uma Semântica de Valor de Verdade distingüe-se, conseqüentemente, de teorias que vêem o estudo do significado como um estudo intra-linguístico ou como o estudo do uso das expressões linguísticas. Não discutirei estas duas correntes da teoria semântica. Menciono-as apenas com o objetivo de localizar a Semântica de Valor de Verdade dentro das linhas que se dedicam à semântica das línguas naturais. Observo que mesmo concordando com a posição que considera que a semântica deve tratar da relação da linguagem com o mundo ou com nossos modelos de mundo, não se pode negar a existência e a necessidade de estudo tanto das relações intra-lingüísticas entre os significados das expressões como da colaboração do contexto de uso para a fixação dos significados. A afirmação de que a escolha entre uma ou outra linha é exclusiva parece-me mais uma resposta à questão ontológica do que é significado do que uma necessária exclusão do tratamento de certas questões sobre o significado. A divisão entre estes três tipos de semântica indica, talvez, uma necessidade metodológica. Da impossibilidade de se estudarem todos os fenômenos semânticos simultaneamente, procura-se ordenar os problemas e atacálos separadamente: as relações internas (linguagem-linguagem); as relações externas (linguagem-mundo); e as relações com os usuários (linguagem-mundofalante). 
Montague, em seu artigo Universal Grammar (1970b), critica, por outro lado, a posição de Chomsky que afirma a centralidade da sintaxe e a conseqüente posição de apêndice do componente semântico. Para ele, as questões semânticas são as principais em um estudo das línguas naturais e como são muitas as regras que podem gerar uma mesma classe de sentenças, não se pode esperar que todas possuam relevância para a compreensão do significado desta. A escolha de Chomsky é para Montague uma escolha invertida (Montague, 1970b, p. 232n.).

"O objetivo básico da semântica é caracterizar as noções de sentença verdadeira (sobre uma determinada interpretação) e de implicação, enquanto que o da sintaxe é caracterizar as diferentes categorias sintáticas, especialmente o conjunto das sentenças declarativas. Pode-se esperar, então, que o objetivo da sintaxe poderia ser realizado de várias maneiras diferentes, apenas algumas das quais forneceriam uma base adequada para a semântica. Parece-me que as análises sintáticas de língua(gen)s particularmente fragmentadas que têm sido sugeridas por gramáticos transformacionais, mesmo se bem sucedidas em caracterizar corretamente as sentenças declarativas destas linguagens, provarão carecer de relevância semântica; e eu não consigo perceber grande interesse na sintaxe, exceto como uma preliminar para a semântica."

\section{A verdade como explicação do significado}

Após a exposição de quais seriam as bases de uma Semântica de Valor de Verdade, cabe perguntar se esta é uma "boa" proposta para o estudo do significado nas línguas naturais. Inicialmente, sobre a aplicação da Convenção $(\mathrm{T})$ às línguas naturais, devemos discutir as objeções levantadas pelo próprio Tarski:(i) a universalidade das línguas naturais e (ii) a distorção a que seriam submetidas as estruturas superficiais das línguas naturais para que a caracterização tarskiana da verdade pudesse ser aplicada a elas.

Uma maneira de expressar o problema causado pela universalidade das línguas naturais seria a metáfora usada por Wittgenstein em suas Investigações Filosóficas. Para ele, a tentativa de compreender a linguagem natural usando modelos da lógica formal é tão vã quanto seria a tentativa de uma mosca presa dentro de uma garrafa de levantá-la. Em outras palavras, nossa percepção estaria de tal maneira envolvida a esta linguagem que seria impossível estudá-la como fenômeno à parte.

Esta metáfora, no entanto, valeria também para um cientista tentando explicar o universo ou o sistema cognitivo humano. Qualquer teoria elaborada pelo ser 
humano envolverá, em maior ou menor grau, o paradoxo de que quem explica faz parte do fenômeno a ser explicado. É possível pensar que este fenômeno é mais agudo para a linguagem natural do que, por exemplo, para qualquer ciência natural; pois estamos estudando o próprio objeto que, de certa maneira, constrói nossa visão de mundo.

A linguagem natural enquanto parte do aparato cognitivo humano é provavelmente um sistema de natureza pragmática que constantemente se adapta a novos contextos. Pode ser considerada um sistema aberto, dependente do contexto, contínuo e indutivo-abdutivo ${ }^{3}$ contrastando qualitativamente com qualquer sistema lógico-dedutivo com suas características de fechamento, independência de contexto e descontinuidade. Poder-se-ia argumentar que as cacterísticas intrínsecas a ambos os sistemas condenam aprioristicamente qualquer estudo que pense a língua natural como um sistema lógico-dedutivo.

Gostaria, então, de tentar esclarecer como pode ser vista a relação entre as linguagens construídas pela lógica e a linguagem humana. As linguagens lógicas, a meu ver, podem ser pensadas como estando para a linguagem humana assim como a Matemática estaria para a Física ou para outras ciências. Ambas fornecem um instrumental rigoroso para a elaboração e teste de modelos e hipóteses. São, no entanto, independentes das ciências a que servem, podendo inclusive antecipar-se ou retardar-se a estas em certos resultados. Não podem ser confundidas com o objeto de estudo em si, ou seja, as linguagens lógicas não são as línguas naturais, assim como a matemática não é a natureza. É descabida, portanto, a crítica de não serem imagens perfeitas destes.

A confusão entre o objeto e a linguagem que o descreve não parece ser privilégio das ciências da linguagem. Afirmações como as de que a natureza é escrita em linguagem matemática e de que Deus é o grande engenheiro, feitas por Galileu, Newton e outros, mostra tendência a confundir os dois planos. Tanto posições de horror ao instrumental lógico-matemático, quanto as que o mistificam vendo nele a resposta para todas as questões colocadas a uma ciência são preconceituosas e não colaboram em uma avaliação de sua utilidade para o estudo da linguagem humana.

A realidade é, possivelmente, multifacetária, diferente e única a cada momento, desordenada e irregular e a linguagem humana, enquanto objeto de estudo e objeto que ao mesmo tempo "se estuda" reflete isto. Deste fato, no entanto, não decorre a impossibilidade de se utilizar um aparato lógico-dedutivo para nos ajudar na compreensão de pelo menos parte de nosso objeto de estudo. Ao nos utilizarmos de um sistema lógico-dedutivo para criar uma imagem de nosso objeto estamos necessariamente nos afastando dele - estamos criando uma abstração, um modelo de realidade. Um modelo é como um retrato simplificado de fenômeno que

(3) Um sistema indutivo parte do particular para chegar ao geral, e um sistema abdutivo deriva hipóteses explanatórias de um conjunto finito de fatos. 
e Literatura, n. 20, p. 119-136, 1992/1993.

desejamos estudar, o qual tenta por a nu certas estruturas e mecanismos. Portanto, a questão da abstração em si não deveria assustar a um pesquisador, pois uma simplificação é uma idealização da realidade é quase que inevitável quando esta se torna nosso objeto de estudo. De que nos adiantaria um explicação da realidade que fosse tão complexa quanto a mesma?

Conta-nos o escritor argentino Jorge Luis Borges, neste conto que é parte do texto "Museo" do livro El Hacedor:

\section{"DEL RIGOR EN LA CIENCIA}

... En aquel Imperio, el arte de la Cartografia logró tal Perfección que el mapa de una sola Provincia ocupada toda una Ciudad, y el mapa del Império, toda una Provincia. Con el tiempo, esos Mapas Desmesurados no satisfacieon y los Colegios de Cartógrafos levantaram um Mapa del Imperio que tenía el tamaño del Imperio y coincidía puntualmente con él. Menos Adictas al Estudio de la Cartografia, las Generactiones Siguientes entendieron que ese dilatado Mapa era Inútil y no sin Impiedad lo entregaron a las Inclemencias del Sol y de los Inviernos. En los desiertos del Oeste perduran despedazadas Ruínas del Mapa, habitadas por Animales y por Mendigos; en todo el País no hay otra reliquia de las Disciplinas Geográficas."

Aproveito a metáfora de Borges para perguntar: de que nos serviria um retrato de tamanho um por um da realidade?

O problema não é então a abstração, a criação de um objeto que não é idêntico a seu original. Uma linguagem construída artificialmente nunca será idêntica à linguagem natural, será apenas um modelo mais ou menos adequado desta ou de alguns de seus aspectos. Um modelo ou uma teoria da linguagem não são bons ou maus por serem abstrações, mas sim são boas más abstrações; julgamento que vai depender dos pressupostos e critérios sob os quais foram construídos, de sua finalidade e dos fatos empíricos que consegue explicar. O risco é o cientista esquecer que está trabalhando com uma aproximação e cair prisioneiro da ficção que ele mesmo criou, passando a tomar esta abstração como o objeto em si mesmo.

Uma teoria mais completa da língua natural seria possivelmente uma teoria "relativística", que levasse em conta a participação e a influência que o falante (o observador) tem dentro do próprio fenômeno e a capacidade de que este falanteobservador possui de se observar enquanto objeto. Uma teoria que desse conta destes fatos seria extremamente complexa, mas não necessariamente impossível. Isto não implica, no entanto, uma banalização da idéia, um "tudo é relativo", segundo o qual qualquer teoria e/ou modelo de um fenômeno é possível à ciência. A verdade é, certamente, um conceito relativo a um "retrato" que construímos da realidade, mas ao mesmo tempo em que existem mil maneiras possíveis de se recortar o mundo, existem outras mil pelas quais este não pode ser recortado. Posso organizar os livros de uma biblioteca pelo nome do autor, assunto, título, ou mes- 

e Literatura, n. 20, p. 119-136, 1992/1993.

mo de maneiras pouco convencionais como cor da capa, peso, número de edição, número de páginas, e assim por diante. Mas não posso organizá-los segundo sua velocidade, sua comida favorita, seu número quântico principal, o tamanho de suas pernas, etc.

Outro aspecto que deve ser considerado quando se debate a adequação de teorias e modelos é o de que uma teoria ou um modelo é de certa maneira "calibrado" à dimensão do fenômeno que deseja explicar. A utilização de fórmulas da Teoria da Relatividade para o estudo da velocidade de um ser humano ou de um carro é desnecessária, pois nesta dimensão suas fórmulas se reduzem à Mecânica Newtoniana. Quanto à linguagem natural, apesar de seu dinamismo, não se pode, $a$ priori, descartar a possibilidade de que certos aspectos desta possam ser estudados de uma maneira "newtoniana" isto é, sem levar em conta o falante-observador. Uma linguagem formal que tentasse imitar o mais acuradamente possível a linguagem natural, poderia, conseqüentemente, nos servir como modelo de alguns aspectos desta.

Ao contrário das linguagens formais, as línguas naturais contêm seus próprios predicados de verdade, o que leva a paradoxos como, por exemplo, o conhecido "Paradoxo do Mentiroso", onde uma pessoa afirma que é mentirosa. Bem, se ela é mentirosa, o que diz deve ser falso. Mas ela afirma que é mentirosa, e se esta afirmação é falsa, então ela não é mentirosa. Como se vê, chegamos à conclusão de que esta pessoa é mentirosa somente se não for mentirosa. Paradoxos como este condenariam uma definição da verdade para a linguagem natural à contradição, $o$ que invalidaria como teoria possível para a linguagem natural, pois a linguagem natural contém todas as linguagens.

Davidson (1967) tem duas respostas alternativas para a questão da universalidade, na qual sua semântica poderia ser feita. A primeira resposta é a de que poder-se-ia construir uma semântica de uma língua natural qualquer - e. g. o português - excluindo-se desta os termos semânticos. Teríamos então uma teoria do significado para um quase-português reservando-se para a metalinguagem - o metaportuguês - os termos pertencentes à teoria semântica. A segunda seria a de se tentar explicar os termos semânticos na própria linguagem-objeto. Ambas as sugestões não estão livres de contestação. No entanto, não me aprofundarei sobre esta discussão. Basta aqui localizar a questão e suas possíveis soluções ${ }^{4}$

Por outro lado, ao se observarem as estruturas elaboradas pelos semanticistas que trabalham nesta linha, como é o caso de Montague, que entram no lugar de $p$ na Convenção $(T)$, torna-se dificil acreditar que elas pertençam à linguagem natural. Esta questão, entretanto, é solucionada se entre a linguagem formal utilizada para descrever a linguagem-objeto e a linguagem-objeto, é estabelecida uma relação de correspondência explícita entre as sentenças da linguagem-objeto e as suas

(4) Sobre esta questão e para bibliografia subseqüente, ver o próprio DAVIDSON, 1967, KRIPKE, 1975 e LYCAN, 1984. 
condições de verdade expressas na linguagem formal. É este o caminho percorrido por Montague em seu artigo "The Proper Treatment of Quantification in English" ao definir uma relação de tradução entre a sintaxe da linguagem-objeto e a sintaxe de sua linguagem lógica intensional, a qual é utilizada para interpretar indiretamente a linguagem-objeto. A ponte nunca explicitada entre a forma lógica subjacente das sentenças da linguagem natural e suas estruturas superficiais seria então feita através de uma correspondência formal entre a sintaxe da linguagem-objeto e a sintaxe da linguagem em que as formas a serem interpretadas estão escritas.

Existe também a possibilidade de se conseguir descrever a estrutura semântica das sentenças de uma língua natural baseada em uma descrição sintática da própria linguagem natural. Em outras palavras, esta descrição por si só já poria a nu a forma da sentença. Os trabalhos na linha da Gramática Gerativa de Chomsky, e alguns dos fragmentos do inglês propostos por Montague (1970a, 1970b) tentam realizar esta tarefa. Por caminhos diferentes ambas as linhas parecem procurar a lógica subjacente às línguas naturais e tentam chegar às leis que subjazem à sintaxe destas.

Cabe salientar, que uma teoria que se utiliza de uma semântica formal como a Gramática de Montague, acredita na possibilidade de uma descrição estrutural das sentenças da linguagem natural (ou de fragmentos desta); ou, no mínimo, na possibilidade de uma definição estrutural de sentença para uma linguagem formal que sirva de modelo, para linguagem natural ou para algum fragmento significativo desta.

Finalmente, não entrarei na discussão de se as condições de verdade esgotam tudo que se refere ao significado de uma sentença. A questão depende obviamente do que uma teoria entende por significado e não existe atualmente, uma única teoria semântica cujo núcleo seja universalmente aceito. A palavra significado utilizada nas diferentes teorias do significado cobre um número grande de noções possivelmente distintas e vagamente relacionadas.

Uma Semântica de Valor de Verdade do tipo elaborado por Montague trata de estudar o que se poderia chamar de forma lógica das sentenças da linguagem natural e de pôr a nu como estas formas lógicas se relacionam a suas estruturas superficiais. A Semântica de Montague busca também demonstrar - coerente com o projeto de Davidson - como as partes estruturais de uma sentença colaboram na determinação de suas condições de verdade.

\section{A verdade e o sentido literal}

A Semântica de Valor de Verdade vai assumir que as partes de uma sentença (as palavras, os sintagmas, as orações) colaboram de uma maneira fixa para a construção das condições de verdade das sentenças. Assume também que a cada momento, em cada contexto, é possível (em tese) dizer de uma sentença declarativa se 
ela é verdadeira ou falsa; se não em relação ao mundo real, em relação a modelos de mundo ou a algum mundo possível. Isto implica que a cada momento uma expressão possui um significado fixo, a que costuma chamar-se de sentido literal.

O dia-a-dia da vida em sociedade parece apoiar-se na crença da literalidade, pois se digo a uma pessoa "Por favor, passe-me uma maçã", ficaria extremamente desconcertada se ao invés de uma maçã a pessoa me entregasse um livro, ou se dissesse a alguém "Estou com fome" e a pessoa respondesse "Então vamos dançar" É provável que se possa dar uma interpretação razoável para estas respostas "estranhas", entretanto, esta interpretação envolveria um número bem maior de pressuposições ${ }^{5}$ sobre as crenças e atitudes dos participantes. No entanto, apesar da literalidade nos parecer extremamente natural, a questão do significado literal é bastante controversa.

Quando a Semântica de Valor de Verdade adotada pela Gramática de Montague diz que uma sentença possui um significado fixo, não está se referindo apenas ao fato de sempre se poder dizer se é verdadeira ou falsa. Este significado fixo deve, ser identificado às condições de verdade da sentença, as quais são particulares a cada sentença. Mas, como determinar estas condições de verdade de uma maneira não simplesmente intuitiva para que a teoria tenha alguma relevância? A Gramática de Montague resolve esta questão adotando o Princípio da Composicionalidade baseado nas idéias desenvolvidas pelo filósofo alemão Gottlob Frege ${ }^{6}$. Este princípio diz que o significado da sentença é determinado pela composição estrutural do significado dos elementos que a compõem. A sentença, então, é vista como composta de unidades menores, hierarquicamente estruturadas.

As expressões possuem ou não um significado literal? A questão da literalidade é de certa maneira semelhante à questão da verdade, pois quando se pergunta sobre a verdade está se perguntando se a relação linguagem-mundo é fixa, essencial, literal. Dentro do paradigma de uma Semântica de Valor de Verdade perguntar sobre a literalidade das expressões é perguntar se sua relação com o mundo é fixa.

Como para a Semântica de Valor de Verdade os significados das unidades sintáticas menores que a sentença são descritos apenas segundo a contribuição que cada unidade traz para as condições de verdade da sentença, não é sua preocupação principal descrever diferenças de significado entre unidades de uma mesma categoria, como por exemplo, a diferença entre o significado entre verbos intransitivos "correr" e "adoecer", ou entre o significado dos sintagmas nominais "um menino" e "um unicórnio" Para a Semântica de Valor de Verdade é essencial explicitar a contribuição de cada uma destas categorias - verbos intransitivos, sintagmas nomi-

(5) Usarei o termo pressuposição neste artigo de uma maneira informal, não assumindo a definição que lhe é dada na lógica.

(6) Ver, por exemplo, FREGE [1893]. 
nais, etc. - para a determinação do valor de verdade das sentenças. A literalidade de uma expressão que compõe uma sentença é aqui principalmente uma literalidade categorial, isto é, assume-se que cada categoria contribui de maneira fixa para as condições de verdade de uma sentença.

Em relação ao significado específico que cada palavra traz consigo, a postulação de um significado fixo para cada expressão é empiricamente insustentável. Diacronicamente, as expressões estão em constante processo de alteração tanto em suas formas quanto em seus significados. Teriamos de buscar o significado literal, então, na sincronia, em certos intervalos temporais arbitrariamente delimitados. Mesmo assim a questão é delicada, pois teríamos de responder a questões como as levantadas por Wittgenstein em suas Investigações Filosóficas, onde este nega que exista uma essência, um traço (objetivo ou não) a todos os objetos designados por uma mesma expressão. Os vários usos de uma mesma expressão lingüística estariam ligados entre si apenas pelo que Wittgenstein chama de "semelhanças de família". Os diferentes significados de uma palavra seriam semelhantes uns aos outros como o são membros de uma mesma família. Se buscarmos um traço comum a todos, não encontraremos, encontraremos sim, traços que são comuns a uns, mas não a outros.

A questão é relevante e possivelmente se aplica a um grande número de expressões das línguas naturais; mas a meu ver não nos obriga a descartar a noção de literalidade que pode ser utilizada como uma aproximação da relação palavramundo, pois há uma literalidade, mesmo que provisória, assumida em qualquer interação linguística. Na Gramática de Montague esta literalidade é definida através de um léxico que nos fornece a categoria sintática da palavra e seu significado e através de regras de combinação semântica fixas que determinam o resultado da combinação das palavras.

A literalidade na Gramática de Montague é uma literalidade relativa, que se define para cada modelo no qual a linguagem é interpretada. Mais ainda, como o significado é uma função de índices (tempos e mundos) a denotações, a denotação de uma expressão não é necessariamente a mesma em todos os tempos e mundos. O que é fixo literal - em cada modelo é esta função de índices a denotações.

\section{Os diferentes tipos de sentenças e a semântica de valor de verdade}

Como vimos, a Semântica de Valor de Verdade assume ser a sentença a unidade de análise, pois é esta a menor unidade lingüística da qual se pode dizer se é verdadeira ou falsa. Mas, evidentemente, não é de qualquer sentença que se pode dizer se é verdadeira ou falsa e por outro lado, há sentenças compostas de mais de uma oração, cada uma das quais possuindo seu próprio valor de verdade. Não se 
pode dizer de sentenças interrogativas e imperativas ${ }^{7}$, pelo menos não trivialmente, que possuam um valor de verdade. Como consequência temos uma semântica que deixaria de lado parte significativa das sentenças da língua. Isto se justifica?

Historicamente a grande maioria das teorias sintáticas e semânticas, não apenas a Semântica de Valor de Verdade, tem elegido a sentença declarativa como a forma básica a partir da qual as outras formas das sentenças são explicadas. Se formos mais atentos em nosso exame verificaremos que não é exatamente a sentença declarativa que é assumida enquanto forma básica, mas sim a oração principal, declarativa, afirmativa e ativa (cf. Givón, 1979, cap. 2).

$\mathrm{O}$ que daria à sentença principal-declarativa-afirmativa-ativa este status tão privilegiado? Para a lógica e para a tradição filosófica que define a verdade como uma correspondência entre a linguagem e o(s) mundo(s), a justificativa é imediata: ela é a menor unidade da qual se pode dizer se é verdadeira ou falsa. A sentença declarativa é privilegiada filosoficamente também por ser através dela que se acumula conhecimento e se transmite informação sobre o(s) mundo(s). $\mathrm{O}$ fato da Semântica de Valor de Verdade privilegiar as sentenças declarativas decorre desta tradição e do fato de que a definição formal de verdade explicita as condições de verdade da sentença declarativa.

Pragmaticamente há uma justificativa interessante para o privilegiamento desta forma. Se assumirmos que a atividade linguística humana envolve principalmente a troca de informação, a sentença principal-declarativa-afirmativa-ativa seria a forma sintática normalmente utilizada para a codificação e transmissão de informação ${ }^{8}$. Evidência disto é dada pela sua maior frequência em textos e conversações?. Isto explicaria as características sintáticas mencionadas acima, pois a forma mais freqüente, mais usual, provavelmente será menos marcada e mais flexível. Do próprio fato de esta ser uma forma usada principalmente para a transmissão de informação nova, pode-se concluir que ela deverá possuir maior flexibilidade para abarcar a expressão de fatos novos, até então não colocados em linguagem.

Outro fato pragmático interessante sobre a sentença principal-declarativaafirmativa-ativa é que ela geralmente implica numa menor complexidade pressuposicional que as sentenças negativas, interrogativas e encaixadas, entre outras, com a única exceção das estruturas existenciais.

(7) Usarei aqui, seguindo LYONS, 1977, declarativo, interrogativo e imperativo em relação a sentenças enquanto membros do sistema da língua, em oposição a asserção, pergunta, ordem, etc., termos que considerei como referindo-se a enunciados.

(8) Entenda-se aqui, informação de qualquer tipo e com qualquer finalidade - não apenas a informação "séria" com a finalidade de aumentar nosso conhecimento sobre o mundo.

(9) Ver GIVÓN, 1979, capítulo 2. 


\section{A verdade e a linguagem - conclusão}

Ao lançarmos um olhar à nossa volta, percebemos que constantemente fazemos uso da palavra e do conceito de verdade, tanto em nosso dia-a-dia quanto na linguagem dita científica. Sentenças como (7) a (11) são extremamente freqüentes:

(7) Não é verdade que eu disse isto.

(8) Este diamante é falso.

(9) A teoria que propõe a existência de buracos negros é falsa.

(10) A verdade é que eles já não se amavam mais.

(11) A: Fortaleza é um belo lugar para se passar as férias.

B: Sim, é verdade.

Um exame superficial nos obriga a admitir que podemos dizer verdadeiro ou falso de entidades as mais variadas, desde objetos do mundo como diamante em (8), fatos, como em (10) e de objetos lingüísticos os mais diversos como, por exemplo, de uma biografia, de uma reportagem, de uma teoria científica, de uma declaração como (9) e (11). Não é, no entanto, de todo objeto linguístico que se pode dizer verdadeiro ou falso; vide, por exemplo, os fonemas, os conectivos, as palavras.

Observando os usos da palavra verdade parece, à primeira vista, que para nós verdade é aquilo que corresponde à realidade, ou seja, seguimos a concepção aristotélica. No entanto, tanto em nosso dia-a-dia, quanto na ciência, esta noção de verdade tem, no mínimo, de ser relativizada. Grande número de pessoas estaria pronto a admitir que a verdade ou a falsidade das sentenças (12), (13), (14) e (15) varia de acordo com o sistema de crenças ou teorias científicas assumidas por indivíduos, grupos ou sociedades.

(12) Deus existe.

(13) A cura de Silvino foi um milagre de Nossa

Senhora do Perpétuo Socorro.

(14) A linguagem é uma capacidade humana inata.

(15) O Universo é infinito.

A aceitação de verdades e falsidade varia, sem dúvida, de um indivíduo a outro, de um grupo social a outro, de uma sociedade a outra. A existência de Deus que para uns é verdade absoluta, é para outros uma mera construção humana. $\mathrm{Na}$ ciência, hipóteses tidas por séculos como verdadeiras, como a de que o Sol gira em torno da Terra, são falseadas. E até no mesmo período histórico podem coexistir teorias que assumem como verdadeiras hipóteses distintas e até contraditórias, como 
é o caso da visão estruturalista da linguagem que a vê enquanto legado social e a visão chomskyana que vê a linguagem como capacidade inata ao homem.

Relativizada ou não, a verdade parece ser uma noção imprescindível ao ser humano. Sem ela não seria possivel a comunicação seja de fatos, idéias científicas, crenças ou sentimentos. Que sentido teria alguém perguntar sobre como está o tempo em um local ao qual se dirige se não pudesse acreditar que a resposta seria verdadeira? Qual seria a importância das religiões se sua verdade não pudesse ser assumida? E como poderia eu expressar meus sentimentos se meus interlocutores $\mathrm{e}$ eu não os assumíssemos como verdadeiros? Como, então, compatibilizar a noção quase que imprescindível de verdade com sua inegável fragilidade? Qual seria sua relação com a linguagem?

$\mathrm{Na}$ literatura filosófica, a discussão sobre a relação entre a verdade e a linguagem é permanente. A posição clássica, a chamada teoria da correspondência, baseia-se na idéia de que a verdade é um enunciado que diz aquilo que é, aquilo que corresponde ao mundo. Citando Aristóteles:

"Dizer do que é, que não é, ou do que não é, que é, é falso, enquanto dizer do que é, que é, ou do que não é, que não é, é verdadeiro." (Aristóteles apud Tarski, 1944).

Para esta visão, o mundo seria dotado de propriedades e essências que se relacionariam de maneira ordenada. Estas se mostrariam a nosso pensamento e seriam refletidas na estrutura deste. Ora, pode-se assumir que a linguagem reflete, pelo menos em parte, a estrutura do pensamento e passa, então, dentro desta postura filosófica, a ser espelho de, pelo menos, parte da estrutura do mundo. Haveria, conseqüentemente, um paralelismo entre a estrutura da linguagem e a estrutura do mundo.

Se na linguagem existem nomes é porque no mundo existem objetos. Se através da linguagem expressamos proposições, estas expressam os estados de coisas possíveis e impossíveis do mundo, a tal ponto que o conjunto de proposições elementares verdadeiras espelharia o mundo. A linguagem é, dentro desta posição filosófica, pelo menos uma das maneiras através da qual o homem pode conhecer as verdades sobre 0 mundo. $O$ que é dito através da linguagem pode ser comparado ao mundo e verificado se verdadeiro ou falso, pois a estrutura da linguagem reflete a estrutura dos possíveis estados de coisas no mundo.

A verdade pode ser vista por outro lado como uma projeção do homem sobre o mundo. Projeção esta feita, pelo menos em parte, através da linguagem. $O$ mundo é considerado caótico em si mesmo, único e multifacetário, composto apenas por entidades e eventos individuais que não se repetem jamais e que não possuem entre si qualquer regularidade ou semelhança. Na natureza não existiriam conceitos, formas, ações ou estados em si. Entidades como "árvore" ou "mamífero", formas como "quadrado" ou "longo", ações como "correr" ou "falar" e estados 
e Literatura, n. 20, p. 119-136, 1992/1993.

como "estar feliz" ou "ser mau" não existiriam enquanto tais, mas seriam convenções humanas. Cada entidade a que chamamos por exemplo, de "árvore" é diferente de qualquer outra entidade à qual aplicamos o mesmo nome. As verdades $e$ falsidades não são ditas, portanto, do mundo-em-si, mas de um mundo convencionado construído pelo homem principalmente através da "legislação da linguagem" A verdade e a falsidade só existem mediante esta convenção, este afastamento đa coisa-em-si que "iguala o não igual" pois a coisa-em-si é única, não repete, não pode ser dita. (cf. Nietzsche, 1873)

Evidentemente, outras posições filosóficas sobre a verdade existem e são possíveis. Não vamos aqui tentar resolver esta questão filosófica tão secular. A verdade pode ser considerada uma questão de coerência dentro de um "esquema" de mundo; uma noção pragmática - uma maneira de chamar conceitos que nos são úteis; ou mesmo um mero ato de fala que significa concordância com o que nosso interlocutor disse. A verdade poderia ser pensada também como uma revelação mística.

Pretendo, como conclusão, chamar a atenção para o fato de que quando se diz verdadeiro ou falso de uma sentença - não importa a posição ontológica a qual assumimos - a noção de verdade acaba funcionando em grande parte das vezes como ponto de contato entre a linguagem e o mundo; seja este mundo algo que nos é dado a priori, seja ele algo construído pelo aparato cognitivo humano do qual a linguagem é um dos principais instrumentos.

\section{BIBLIOGRAFIA}

CHOMSKY,N. (1957). Syntactic Structures. Haia:Mouton.

DAVIDSON,D. (1967). "Truth and Meaning" In: D. Davidson (1984).

DAVIDSON,D.(1970). "Semantics for natural languages". In: D. Davidson (1984).

DAVIDSON, D. (1984). Inquiries into muth \& interpretation. Oxford: Blackwell.

FREGE,G.[1893]."On sense and Meaning” In: P. Geach \& M. Black (eds.) (1952).

Translations from the pphilosophical writings of Gotlob Frege. Oxford: Blackwell.

GIVÓN,T. (1979). On understanding grammar. New York: Academic Press.

KEMPSON,R.(1977). Semantic Theory. Cambridge: Cambridge Univerdity Press.

KRIPKE,S.(1975). "Outline of a theory of truth". Journal of Philosophy 72.

LYCAN,W.G. (1984). Logical form in natural language. Cambridge, Mass.: The MIT Press. LYONS,J. (1977). Semantics. Cambridge: Cambridge University Press.

MONTAGUE,R. (1970a). "English as a Formal Language." In: R. Thomason (ed.) (1979). MONTAGUE,R. (1970b)."Universal Grammar". In: R. Thomason (ed.) (1979).

MONTAGUE,R. (1973)."The Proper Treatment of Quantification in Ordinary Englih." In: R. Thomason (ed.) (1979).

MÜLLER,A.L.(1988).Um estudo sobre a Gramática de Montague e sua aplicação ao Português. Tese de Mestrado da UFPR.

NIETZSCHE,F.W.[1873]. "Sobre a verdade e a mentira no sentido extra-moral" In: F.W. Nietzsche (1978). Obras Incompletas. São Paulo: Abril Cultural (Os Pensadores). 

e Literatura, n. 20, p. 119-136, 1992/1993.

STEGMULLER,W. (1977). A filosofia comtemporânea: Introdução critica, vol. 2. São Paulo:EPU/EDUSP.

TARSKI,W.[1933]. "The concept of truth in formalized languages". In: W.Tarski (1969).Logic, semantics and metamathematics, pp. 152-258. Oxford; Clarendon Press.

TARSKI,W. (1944). "The semantic conception of truth". Philosophy an Phenomenological Research, 4:341-375.

\begin{abstract}
This article is mostly about the philosophical foundationas of the linguistic program of the north-american logician Richard Montague (1930-1970). Montague's goal was to build up a truth conditional semantics for natural languages by means of a model-theoretic and possible-worlds semantics and making use of an intensional formal language. More specifically, I discuss the choice of a truth conditional semantics and its validity as a means of analysing meaning in natural languages.
\end{abstract}

Key-Words: semantics, meaning, truth-conditional semantics. 